\title{
Autoconfiança no manejo das intercorrências de saúde na escola: contribuições da simulação in situ*
}

\author{
Jaqueline Brosso Zonta ${ }^{1}$ \\ (D) https://orcid.org/0000-0002-9602-4087 \\ Aline Helena Appoloni Eduardo² \\ (D) https://orcid.org/0000-0003-1577-3383 \\ Maria Verônica Ferrareze Ferreira ${ }^{3}$ \\ (iD) https://orcid.org/0000-0002-1152-9538 \\ Gabriela Heleno Chaves ${ }^{2}$ \\ (D) https://orcid.org/0000-0001-9112-7813 \\ Aline Cristiane Cavicchioli Okido ${ }^{2}$ \\ (iD https://orcid.org/0000-0003-4309-5612
}

\footnotetext{
* Artigo extraído da dissertação de mestrado "Autoconfiança no manejo das intercorrências de saúde na escola entre professores da educação infantil e fundamental I", apresentada à Universidade Federal de São Carlos, São Carlos, SP, Brasil. O presente trabalho foi realizado com apoio da Coordenação de Aperfeiçoamento de Pessoal de Nível Superior - Brasil (CAPES) - Código de Financiamento 001.

Universidade Federal de São Carlos, São Carlos, SP, Brasil.

2 Universidade Federal de São Carlos, Departamento de Enfermagem, São Carlos, SP, Brasil

3 Universidade de São Paulo, Escola de Enfermagem de Ribeirão Preto, Centro Colaborador da OPAS/OMS para o Desenvolvimento da Pesquisa em Enfermagem, Ribeirão Preto, SP, Brasil.
}

Objetivo: analisar as contribuições da simulação in situ na autoconfiança de professores da educação infantil efundamental I com relação ao manejo inicial das intercorrências de saúde na escola. Método: estudo quase experimental, do tipo pré e pós-teste. Aplicou-se em 76 professores dois instrumentos pré e pós simulação in situ, os quais foram: escala visual analógica de autoconfiança dos professores para manejo das intercorrências de saúde na escola e questionário para avaliar o conhecimento na temática. A atividade educativa foi composta por quatro cenários de simulação in situ. Os dados foram analisados mediante estatística descritiva e analítica, utilizou-se regressão linear univariada e multivariada. Resultados: a comparação dos resultados de autoconfiança pré e pós simulação in situ identificou promoção da autoconfiança $(p<0,001)$ em especial para aqueles professores com menor tempo de experiência profissional $(p=0.008)$, sem vivência prévia semelhante $(p=0.003)$ e que participaram ativamente da simulação $(p=0.009)$. Conclusão: os professores sentemse pouco confiantes para manejar intercorrências de saúde. A simulação in situ elevou a percepção da autoconfiança entre os professores.

Descritores: Criança; Serviços de Saúde Escolar; Enfermagem; Primeiros Socorros; Simulação; Confiança.

\section{Como citar este artigo}

Zonta JB, Eduardo AHA, Ferreira MVF, Chaves GH, Okido ACC. Self-confidence in the management of health complications atschool: contributions of the in situ simulation. Rev. Latino-Am. Enfermagem. 2019;27:e3174. [Access †_十_ ']; Available in: DOI: http://dx.doi.org/10.1590/1518-8345.2909.3174. 


\section{Introdução}

$\mathrm{Na}$ infância ocorre acentuado desenvolvimento imunológico e neurológico, o que torna a criança vulnerável a doenças e acidentes, bem como mais susceptível a complicação e óbito(1). As intercorrências de saúde na infância podem ser subdivididas entre as relacionadas a doenças, como os agravos respiratórios e gastrointestinais, e relacionadas a acidentes, como acidente de trânsito, envenenamento, afogamento, queimadura, queda e obstrução de vias aéreas ${ }^{(1-2)}$.

A maior parte dos agravos relacionados à saúde na infância acontecem no domicílio. No entanto, o ambiente escolar não está isento destas intercorrências, uma vez que as crianças permanecem grande parte do dia neste local(3-7). Assim, as ações de prevenção e promoção à saúde são requeridas nas escolas e, para tanto, é fundamental que professores e outros profissionais que atuam neste ambiente sejam capazes de manejar os primeiros socorros ${ }^{(5-9)}$.

Os primeiros socorros no ambiente escolar geralmente são conduzidos pelos professores ${ }^{(10-11)}$, no entanto, estes apresentam baixos níveis de conhecimento na temática(10-12). Revelam não possuir qualquer tipo de capacitação de modo contínuo e sistematizado e que, quando necessário, empregam conhecimentos obtidos em leituras e/ou experiências prévias, além do senso comum(13). A literatura reforça que, sentimentos negativos como insegurança, medo e nervosismo são potencializados diante das intercorrências de saúde no contexto escolar, fragilizando a autoconfiança dos professores ${ }^{(14-15)}$. Nesta perspectiva, esta investigação compartilha do pressuposto de que a autoconfiança aliada às experiências prévias e ao conhecimento pode promover um manejo seguro das intercorrências de saúde(16-17)

A literatura apresenta a utilização de diversas estratégias de ensino que objetivam proporcionar habilidade e conhecimento sobre o manejo de intercorrências de saúde entre os professores como aula expositiva, cartilha educativa e vídeos ${ }^{(7,18)}$. Contudo, não foram acessados estudos que adotaram a estratégia de simulação entre os professores, sendo comum entre os profissionais da saúde ${ }^{(16,19-21)}$

Dentre as possibilidades de abordagem utilizando a simulação, este estudo adotou a simulação in situ. Denomina-se simulação in situ toda atividade baseada em simulação que ocorre no contexto real, isto é, os cenários simulados são construídos no próprio ambiente de trabalho ${ }^{(22-23)}$. Ela facilita o acesso dos profissionais à capacitação e potencializa o treinamento de equipes reais de profissionais ${ }^{(23)}$. Além disso, promove a fidelidade dos cenários à medida que o contexto de aprendizagem se assemelha ao contexto da prática(22).

Nesta direção, estudo demonstra que a simulação in situ pode aumentar os níveis de confiança, implicando na melhora do reconhecimento e gerenciamento de situações $^{(24)}$. Assim, esta investigação inova ao propor uma intervenção educativa mediada pela simulação in situ entre professores de educação infantil e fundamental I.

Diante do exposto, estabeleceram-se as seguintes questões de pesquisa: uma atividade educativa mediada pela simulação in situ promove autoconfiança em relação ao manejo das intercorrências de saúde na escola? Quais os fatores associados à promoção da autoconfiança após atividade educativa mediada pela simulação in situ?

Assim, o objetivo deste estudo foi analisar as contribuições da simulação in situ na autoconfiança de professores da educação infantil e fundamental I com relação ao manejo inicial das intercorrências de saúde na escola.

\section{Método}

Estudo quase experimental, do tipo pré e pósteste ${ }^{(25)}$, desenvolvido em quatro instituições públicas de educação infantil e fundamental I de um município do interior do estado de São Paulo, no período de maio a outubro de 2017.

Com relação aos participantes do estudo, os critérios de inclusão foram: ser professor da educação infantil ou fundamental I, ter idade igual ou superior a 18 anos e ter no mínimo três meses de experiência profissional. Foram excluídos aqueles que se encontravam de férias ou licença e os professores que não estavam presentes em todos os encontros previstos. Assim, inicialmente, 113 professores aceitaram participar do estudo, no entanto, 37 não compareceram a todos os encontros e foram excluídos, permanecendo 76 professores, média de 19 por escola. Não houve recusa.

A produção do material empírico iniciou-se com a identificação das escolas públicas de educação infantil e fundamental I do município. A seguir, de forma aleatória, os diretores foram contatados a fim de explicar sobre a pesquisa e solicitar autorização para utilizar duas horas de trabalho pedagógico coletivo (HTPC). Faz-se importante registrar que a Secretaria Municipal de Educação autorizou o estudo previamente e que as pesquisadoras não mantinham relação anterior com as instituições escolhidas.

Nas quatro escolas incluídas no estudo, foram agendados três encontros, conforme disponibilidade. No primeiro encontro, os professores elegíveis que aceitaram o convite responderam aos instrumentos de pesquisa, os quais foram: instrumento de caracterização dos professores; escala visual analógica (EVA) de autoconfiança dos professores para manejo das intercorrências de saúde na escola; e questionário de avaliação do conhecimento para atuar diante de intercorrências de saúde na escola.

A EVA de autoconfiança dos professores para manejo das intercorrências de saúde na escola é composta por 
12 itens que tratam sobre a percepção da confiança dos professores em avaliar e garantir a segurança do local em que ocorre a intercorrência, avaliar e constatar a necessidade de chamar por ajuda e avaliar e oferecer o primeiro atendimento nas seguintes situações: febre, engasgo, crise convulsiva, queda com ferimento profundo e sangramento e parada cardiorrespiratória. Cada item da escala possui uma linha horizontal de dez centímetros com descritores nas extremidades: "nada confiante" à esquerda e "completamente confiante" à direita. Para estabelecer a pontuação o respondente indica ao longo da linha o nível de autoconfiança que possui no momento. A interpretação dos resultados se dá pela mensuração do espaço obtido entre a extremidade à esquerda e o ponto sinalizado pelo respondente, com uma régua graduada em centímetros. A escala permite acessar o nível de autoconfiança para cada item e também mensurar a média geral de autoconfiança(26).

O questionário de avaliação do conhecimento para atuar diante de intercorrências de saúde na escola foi construído pelas próprias pesquisadoras e baseou-se em análise da literatura nacional e internacional e em discussões entre os membros do grupo de pesquisa. A seguir, o conteúdo foi validado por 11 juízes especialistas. Possui 42 itens relativos ao atendimento inicial de um escolar em situação de intercorrência de saúde como crise convulsiva, parada cardiorrespiratória, afogamento, entre outras. Para cada item há três possibilidades de resposta: verdadeiro (1), falso (0) e não sei (0). Deste modo, o escore mínimo do questionário é zero e o máximo 42.

A seguir foi disponibilizado via e-mail a cartilha intitulada "Primeiros Socorros na escola: orientações para professores da educação infantil pré-escolar e do ensino fundamental $I^{\prime \prime(7)}$. A leitura da cartilha constituise numa etapa da simulação denominada "prébriefing", ou seja, toda orientação, tarefa ou atividade projetada pelo educador que ocorre em momento anterior ao desenvolvimento do cenário(27-28). Esta etapa tem como objetivo aproximar os participantes à temática de modo a potencializar o desempenho no cenário simulado e na discussão posterior. Aula teórica, vídeos e leitura estão entre as estratégias comumente adotadas no pré-briefing(27). Faz-se importante registrar que, por tratar-se de leitura individual fora do horário reservado para coleta de dados e, portanto, difícil de ser controlada, esta atividade não foi considerada como critério de participação na pesquisa. Todavia, ao serem questionados, de maneira geral, os professores afirmaram ter realizado a leitura prévia.

A implementação da atividade educativa mediada pela simulação in situ se deu no segundo e no terceiro encontro a partir de quatro cenários simulados desenvolvidos na própria escola. Os cenários foram elaborados a partir de um referencial metodológico que compreende as seguintes etapas: identificação do tema, objetivos da simulação, participantes, pré-briefing, cenário e processo de debriefing (28). A construção dos cenários fundamentouse nas evidências científicas atuais sobre a temática, bem como na experiência prévia das pesquisadoras. Os quatro templates foram submetidos à validação de aparência e conteúdo por 11 juízes especialistas. Além disto, os cenários foram submetidos a um teste piloto com graduandos do curso de pedagogia e educação especial durante evento interno da universidade.

O objetivo geral da atividade educativa mediada pela simulação in situ foi proporcionar o aprendizado do manejo inicial de quatro intercorrências de saúde que podem ocorrer na escola, as quais foram: obstrução das vias áreas por corpo estranho/engasgo, queda com ferimento profundo/sangramento, crise convulsiva e parada cardiorrespiratória. A participação ativa nos cenários foi voluntária, todavia, todos foram estimulados a vivenciar ativamente pelo menos um cenário. Para cada situação, dois professores participavam ativamente, ou seja, eram inseridos no cenário para realizar o atendimento, e os demais permaneciam como observadores. Cada cenário foi desenvolvido uma vez em cada escola, portanto, 32 professores atuaram e 44 observaram. No último encontro, após finalização da atividade educativa, os professores responderam aos mesmos instrumentos aplicados anteriormente, exceto o de caracterização.

Os dados foram codificados e incluídos em banco formatado no editor de planilhas Excel, por meio de dupla digitação. Após a validação, o banco de dados foi exportado para o software Statistical Package for Social Science (SPSS) versão 9.2, no qual foram processadas as análises estatísticas. Foram consideradas como variáveis respostas a média do escore de autoconfiança após simulação in situ e a média da diferença entre os escores de autoconfiança pré e pós simulação in situ, denominada "promoção da autoconfiança". As variáveis independentes foram: sexo (variável categórica), idade (variável categórica e/ou numérica), escolaridade (variável categórica), filhos (variável dicotômica e/ou numérica), experiência profissional em anos (variável numérica); participação ativa (variável dicotômica); vivência anterior com intercorrência de saúde na escola ou em outro ambiente, denominada "vivência anterior" (variável dicotômica) e promoção do conhecimento (variável numérica obtida a partir da diferença entre os escores de conhecimento pré e pós simulação in situ).

$\mathrm{Na}$ análise estatística descritiva, as variáveis categóricas foram apresentadas como frequência absoluta e relativa, e as numéricas como medidas de tendência central, variabilidade e posição. Para comparação dos escores médios de autoconfiança pré e pós simulação 
in situ utilizou-se o teste de Wilcoxon para amostras relacionadas. Para a comparação das variáveis respostas entre as variáveis independentes empregou-se o teste de Mann-Whitney para as variáveis dicotômicas e KruskalWallis para aquelas com mais de duas categorias. Segundo os testes de normalidade de Shapiro-Wilk e de KolmogorovSmirnov, não houve distribuição normal das variáveis.

A correlação das variáveis numéricas foi calculada a partir do coeficiente de correlação de Spearman. Adotouse, para os testes, um nível de significância de $5 \%{ }^{(29)}$. Por fim, para analisar os fatores relacionados à autoconfiança foi utilizada a análise de regressão linear univariada e multivariada, com critério Stepwise de seleção.

Destaca-se que foi verificada a consistência interna dos instrumentos utilizados na coleta de dados pelo coeficiente alfa de Cronbach, considerando alta consistência valores acima de $0.70^{(29)}$. Assim, o valor do a de Cronbach da EVA de autoconfiança dos professores para manejo das intercorrências de saúde na escola e do questionário de avaliação do conhecimento foram 0,94 e 0,81, respectivamente.

Faz-se importante registrar que a atividade educativa mediada pela simulação in situ contou com a participação de quatro estudante de graduação, duas mestrandas e duas docentes, e estava vinculada a uma atividade de extensão. Todavia, a aplicação dos instrumentos foi conduzida exclusivamente pela pesquisadora principal.

O projeto foi aprovado pelo Comitê de Ética em Pesquisa da Universidade Federal de São Carlos sob o CAEE:65118117.9.0000.5504. Todos os professores receberam uma via do Termo de Consentimento Livre e Esclarecido (TCLE), o qual informou sobre os objetivos do estudo, os procedimentos para coleta de dados, os possíveis riscos/constrangimentos, os benefícios, bem como a garantia de sigilo e o respeito ao desejo de participarem ou não da pesquisa.

\section{Resultados}

Foram participantes do estudo 76 professores da educação infantil e fundamental I. A maioria era do sexo feminino (97\%), com média de 39,4 anos de idade e de 12,6 anos de experiência de trabalho.

O escore médio de autoconfiança pré simulação in situ foi 4.13 , desvio padrão \pm 1.57 , escore mínimo de 1.20, mediana 3.81 e escore máximo de 9.11. Após simulação in situ, o escore médio de autoconfiança foi 6.92, desvio padrão \pm 1.84 , escore mínimo de 2.07, mediana 6.78 e escore máximo de 9.78. A diferença das médias de autoconfiança entre pré e pós, a partir do teste de Wilcoxon para amostras relacionadas, revelou $p<0,001$.

Observou-se aumento no escore médio de autoconfiança de 3.03. O item que apresentou maior diferença entre os escores médios pré e pós (5.18) foi: "eu me sinto confiante para oferecer o primeiro atendimento a uma criança que está convulsionando". E o item com menor diferença (0.03) foi: "eu me sinto confiante para reconhecer quando uma criança está com febre".

A Tabela 1 apresenta os escores de autoconfiança pré e pós simulação in situ para cada um dos 12 itens da escala, bem como a promoção da autoconfiança.

Tabela 1 - Autoconfiança dos professores para atuarem em situações de intercorrências de saúde na escola pré e pós simulação in situ. São Carlos, SP, Brasil, 2017

\begin{tabular}{|c|c|c|c|}
\hline Item & Autoconfiança pré & Autoconfiança pós & $\begin{array}{c}\text { Promoção } \\
\text { autoconfiança }\end{array}$ \\
\hline $\begin{array}{l}\text { 1. Eu me sinto confiante para avaliar a segurança do local diante de uma criança } \\
\text { apresentando uma intercorrência de saúde, seja por doença ou acidente. }\end{array}$ & 3.64 & 6.09 & 2.45 \\
\hline $\begin{array}{l}\text { 2. Eu me sinto confiante para identificar a necessidade de chamar ajuda do Serviço } \\
\text { Médico de Urgência (SAMU) pelo número telefônico } 192 .\end{array}$ & 6.15 & 8.26 & 2.11 \\
\hline 3. Eu me sinto confiante para reconhecer quando uma criança está convulsionando. & 3.88 & 7.52 & 3.64 \\
\hline $\begin{array}{l}\text { 4. Eu me sinto confiante para oferecer o primeiro atendimento a uma criança que está } \\
\text { convulsionando. }\end{array}$ & 1.88 & 7.06 & 5.18 \\
\hline $\begin{array}{l}\text { 5. Eu me sinto confiante para oferecer o primeiro atendimento a uma criança que } \\
\text { sofreu uma queda. }\end{array}$ & 3.75 & 6.53 & 2.78 \\
\hline $\begin{array}{l}\text { 6. Eu me sinto confiante para oferecer o primeiro atendimento a uma criança que } \\
\text { sofreu um ferimento que está sangrando muito. }\end{array}$ & 3.68 & 6.39 & 2.71 \\
\hline $\begin{array}{l}\text { 7. Eu me sinto confiante para reconhecer quando uma criança se encontra } \\
\text { desacordada e sem respirar. }\end{array}$ & 3.27 & 6.08 & 2.81 \\
\hline $\begin{array}{l}\text { 8. Eu me sinto confiante para oferecer o primeiro atendimento a uma criança } \\
\text { desacordada e sem respirar. }\end{array}$ & 1.35 & 5.53 & 4.18 \\
\hline 9. Eu me sinto confiante para reconhecer quando uma criança está engasgando. & 4.56 & 6.93 & 2.37 \\
\hline $\begin{array}{l}\text { 10. Eu me sinto confiante para oferecer o primeiro atendimento a uma criança que } \\
\text { está engasgando. }\end{array}$ & 2.61 & 6.42 & 3.81 \\
\hline 11. Eu me sinto confiante para reconhecer quando uma criança está com febre. & 8.19 & 8.16 & 0.03 \\
\hline $\begin{array}{l}\text { 12. Eu me sinto confiante para oferecer o primeiro atendimento a uma criança que } \\
\text { está com febre. }\end{array}$ & 6.72 & 8.09 & 1.37 \\
\hline
\end{tabular}


Os escores médios de autoconfiança pós simulação in situ e da promoção da autoconfiança segundo as variáveis categóricas estão apresentados na Tabela 2 .

A matriz de correlação envolvendo as variáveis numéricas e as variáveis respostas está apresentada na Tabela 3.
A análise de regressão linear univariada foi empregada neste estudo para avaliar a relação das variáveis independentes com o escore médio da autoconfiança pós simulação in situ e com a promoção da autoconfiança, conforme apresentado na Tabela 4.

Tabela 2 - Distribuição do escore médio de autoconfiança pós simulação in situ e do escore médio de promoção da autoconfiança segundo as variáveis categóricas. São Carlos, SP, Brasil, 2017

\begin{tabular}{|c|c|c|c|c|c|}
\hline Variáveis & N (\%) & Autoconfiança pós & $p$ & Promoção autoconfiança & $p$ \\
\hline Sexo & & & $0.844^{*}$ & & $0.617^{*}$ \\
\hline Feminino & $74(97.4)$ & 6.91 & & 2.85 & \\
\hline Masculino & $2(2.6)$ & 7.32 & & 3.61 & \\
\hline Idade & & & $0.077^{\dagger}$ & & $0.289^{\dagger}$ \\
\hline$<40$ anos & $34(47.2)$ & 7.41 & & 3.32 & \\
\hline 40-49 anos & $25(34.7)$ & 6.50 & & 2.84 & \\
\hline$>=50$ anos & $13(18.1)$ & 6.63 & & 2.42 & \\
\hline Sem resposta & 4 & & & - & \\
\hline Escolaridade & & & $0.304^{*}$ & & $0.610^{*}$ \\
\hline Superior & $27(36.5)$ & 7.32 & & 3.05 & \\
\hline Pós-graduação & $47(63.5)$ & 6.64 & & 2.76 & \\
\hline Sem resposta & 2 & & & - & \\
\hline Experiência profissional & & & $0.001^{\dagger}$ & & $0.011^{\dagger}$ \\
\hline$<10$ anos & $33(44.6)$ & 7.83 & & 3.31 & \\
\hline 10-19 anos & $26(35.1)$ & 6.59 & & 3.12 & \\
\hline$>=20$ anos & $15(20.3)$ & 5.69 & & 1.67 & \\
\hline Sem resposta & 2 & & & - & \\
\hline Filhos & & & $0.920^{*}$ & & $0.819^{*}$ \\
\hline Não & $22(29.3)$ & 6.82 & & 2.83 & \\
\hline Sim & $53(70.7)$ & 6.92 & & 2.95 & \\
\hline Sem resposta & 1 & & & - & \\
\hline Vivência anterior & & & $0.131^{*}$ & & $0.002^{\star}$ \\
\hline Não & $16(21.3)$ & 7.59 & & 4.10 & \\
\hline Sim & $59(78.7)$ & 6.70 & & 2.50 & \\
\hline Sem resposta & 1 & & & - & \\
\hline Participação ativa & & & $0.009^{\star}$ & & $0.375^{*}$ \\
\hline Não & $44(57.9)$ & 6.53 & & 2.71 & \\
\hline Sim & $32(42.1)$ & 7.48 & & 3.09 & \\
\hline
\end{tabular}

Tabela 3 - Coeficiente de correlação de Spearman entre as variáveis respostas e as variáveis numéricas. São Carlos, SP, Brasil, 2017

\begin{tabular}{lcccc}
\hline Variáveis & Idade & Experiência profissional & Número de filhos & Promoção do conhecimento \\
\hline Escore médio de autoconfiança após atividade educativa & $-\mathbf{0 . 2 5 8 ^ { * }}$ & $-\mathbf{0 . 3 7 8 ^ { * }}$ & -0.132 & -0.083 \\
Escore médio da promoção da autoconfiança & -0.202 & -0.187 & 0.007 & 0.148 \\
\hline
\end{tabular}
$* p<0,005$

Tabela 4 - Efeito das variáveis independentes no escore médio de autoconfiança pós simulação in situ e na promoção da autoconfiança, segundo modelo de regressão linear univariada. São Carlos, SP, Brasil, 2017

\begin{tabular}{lcccccc}
\hline Variável & \multicolumn{3}{c}{ Autoconfiança pós } & \multicolumn{2}{c}{ Promoção autoconfiança } \\
\hline Idade & ${\text { Beta* }(E P)^{\dagger}}^{\dagger}$ & Valor- $\boldsymbol{p}$ & $\mathbf{R}^{2 \ddagger}$ & \multicolumn{2}{c}{ Beta* (EP) $^{\dagger}$} & $\mathbf{R}^{\mathbf{2}}$ \\
Sexo & $-0.26(0.12)$ & $\mathbf{0 . 0 3 2}$ & 0.0651 & $-0.21(0.12)$ & 0.088 \\
Escolaridade & $3.08(15.72)$ & 0.845 & 0.0005 & $7.71(15.52)$ & 0.620 & 0.0421 \\
Filhos & $-5.31(5.26)$ & 0.316 & 0.0142 & $-2.60(5.31)$ & 0.626 & 0.0034 \\
Experiência profissional & $-0.15(0.13)$ & 0.262 & 0.0184 & $0.01(0.13)$ & 0.953 & 0.0001 \\
Vivência anterior & $-0.38(0.11)$ & $\mathbf{0 . 0 0 1}$ & 0.1423 & $-0.19(0.12)$ & 0.114 & 0.0352 \\
Promoção conhecimento & $-9.22(6.03)$ & 0.131 & 0.0314 & $-19.29(5.68)$ & 0.001 & 0.1400 \\
Participação ativa & $-0.08(0.12)$ & 0.478 & 0.0069 & $0.15(0.11)$ & 0.199 & 0.0229 \\
\hline
\end{tabular}

*Beta = Coeficiente de regressão; ${ }^{+} \mathrm{EP}=$ erro padrão de beta; ${ }^{\ddagger} \mathrm{R}^{2}=$ Coeficiente de determinação

Em seguida, as variáveis estatisticamente significantes entraram no modelo de regressão linear multivariado pelo método de Stepwise Backward Wald.
Verificou-se que a "experiência profissional" manteve relação significativa com o escore médio de autoconfiança pós simulação in situ $(\mathrm{p}=0.008)$, portanto, os professores 
que apresentaram maiores escores médios de autoconfiança pós atividade educativa possuíam menor tempo de experiência profissional. A variável "vivência anterior" manteve relação significativa com a promoção da autoconfiança $(p=0.003)$, isto significa que os professores que não relataram vivência prévia com intercorrência de saúde tiveram maior promoção da autoconfiança.

\section{Discussão}

A partir da caracterização, identificamos que $97 \%$ dos participantes eram do sexo feminino e tinham em média 39,4 anos de idade. Estudo que teve como objetivo determinar a conscientização, atitudes e práticas de professores indianos sobre os primeiros socorros, corrobora a medida quanto à prevalência feminina, uma vez que $82,2 \%$ dos participantes eram mulheres $^{(12)}$. No que se refere à idade dos professores, os resultados encontrados em estudo realizado na Coréia diferem desta investigação, no qual a maioria (34,2\%) tinha entre 20 e 29 anos de idade ${ }^{(15)}$.

A maioria dos participantes $(78,7 \%)$ afirmou ter vivenciado uma situação de urgência ao longo da vida, seja no ambiente escolar ou não. Este dado assemelha-se aos resultados de outras pesquisas, as quais reforçam que as intercorrências de saúde entre as crianças no contexto escolar são comuns ${ }^{(11,18)}$. Vivenciar intercorrências de saúde pode estar relacionado à presença de crianças no núcleo familiar, haja visto que $70 \%$ dos professores declararam ter filhos. Em estudo brasileiro que avaliou o conhecimento de professores e demais profissionais que atuam no ambiente escolar após receberem treinamento de primeiros socorros, a maioria $(71,4 \%)$ também informou já ter vivenciado uma situação de intercorrência(30).

Entre o item com menor escore médio de autoconfiança destaca-se aquele referente ao primeiro atendimento a uma criança desacordada e sem respirar, com escore médio de 5,53 após simulação in situ. Segundo a literatura, as especificidades anatômicas e fisiológicas do público infantil exigem um manejo diferenciado da situação(31), o que pode intensificar os sentimentos de insegurança.

De acordo com os resultados, a necessidade de intervir diante de uma intercorrência de saúde provoca sentimento de insegurança entre os professores. Tal resultado corrobora com estudo qualitativo que objetivou compreender o papel dos professores diante de situações de urgência e emergência na escola(14). Segundo este estudo, é comum o despreparo, a insegurança e o nervosismo dos professores para o atendimento inicial de intercorrências ${ }^{(14)}$. Essa problemática também é observada em estudo internacional(15).
A participação na simulação in situ promoveu a autoconfiança dos participantes reiterando a relevância de cursos e treinamentos voltados para formação técnica e emocional para manejar intercorrências de saúde no ambiente escolar(32). Investigação internacional também atribuiu a autoconfiança dos professores aos treinamentos constantes sobre primeiros socorros ${ }^{(15)}$.

Os resultados apontaram que os professores que não tinham vivenciado intercorrências de saúde ao longo da vida apresentaram maior diferença de escore de autoconfiança após simulação in situ, o que é explicado pelos seus escores baixos de autoconfiança pré simulação. Tal resultado pode ser um indicativo dos efetivos benefícios das intervenções educativas entre professores que não possuem experiências prévias. Nesta perspectiva, apoiamos no pressuposto de que repetidas experiências melhoram a autoconfiança(17). Investigação qualitativa que analisou os conhecimentos e experiências de educadores infantis sobre primeiros socorros reforça o exposto ao apresentar o êxito de uma das professoras no atendimento de um bebê com obstrução de via aérea superior. Segundo os autores, sua conduta deu-se em virtude das suas vivências prévias ${ }^{(33)}$.

Ademais, a análise de regressão multivariada apontou que os professores com maiores escores médios de autoconfiança após simulação in situ foram aqueles com menor tempo de experiência profissional. Não foi encontrado nenhum estudo desenvolvido com professores que possa apoiar este achado, no entanto, estudo que buscou associar a satisfação com as atividades acadêmicas e as variáveis sociodemográficas de 170 estudantes de enfermagem revelou em seus resultados que os estudantes mais jovens ficaram mais satisfeitos com o curso e com a oportunidade de desenvolvimento( ${ }^{(34)}$.

Este estudo assumiu a simulação in situ enquanto estratégia metodológica para produzir a atividade educativa proposta e identificou associação significativa entre participação ativa nos cenários simulados e o escore médio de autoconfiança após simulação in situ, corroborando com outras investigações que utilizaram a simulação, as quais reforçam que a participação ativa propicia pensamento crítico e reflexão, consequentemente expandindo a confiança ${ }^{(35)}$. Acrescentam ainda que o fazer está vinculado aos aspectos cognitivos, às habilidades e competências para determinada situação, ou seja, a participação ativa é eficaz e propicia a aprendizagem significativa(36). A vivência de simulações apresenta-se positiva em relação à aquisição e aumento do nível de autoconfiança e aprendizagem ${ }^{(37-38)}$.

A autoconfiança para atender uma criança em crise convulsiva também foi fortalecida após simulação in situ, assemelhando-se aos resultados de um estudo internacional que verificou o efeito da educação em 
saúde sobre o conhecimento, habilidades e atitudes diante da epilepsia, entre professores estagiários. De acordo com os pesquisadores, os professores tinham restrito conhecimento e habilidades e demostraram atitudes negativas em relação à epilepsia, contudo, após intervenções educacionais sobre a temática, apresentaram níveis significativos de melhoria quanto às atitudes e habilidades em gerenciar a doença de forma segura(19).

Identificou-se também que os itens que obtiveram menor diferença pré e pós atividade educativa mediada pela simulação in situ foram os relacionados à confiança em reconhecer e manejar uma criança com febre, ou seja, os professores já apresentavam bons índices de autoconfiança com relação ao cuidado com a febre antes da atividade. Tal achado contrapôs com o resultado apresentado por um estudo internacional que buscou identificar o conhecimento, a ansiedade e o manejo da febre entre professores de uma creche(39), o qual identificou altos níveis de ansiedade diante de uma criança com febre ${ }^{(39)}$.

Embora os resultados deste estudo encontrem respaldo na literatura, é válido apontar algumas limitações. A principal refere-se ao delineamento, o qual não incorporou um grupo controle, impossibilitando a identificação de relações de causa e efeito. Outra limitação importante diz respeito ao controle não sistematizado da leitura da cartilha entre os professores. Ainda assim, estas limitações não revogam os resultados da pesquisa, mas indicam a necessidade de estudos futuros, com delineamento longitudinal.

Por fim, esta investigação avança no conhecimento à medida que tem potencial para subsidiar o planejamento das ações de educação em saúde na escola. A identificação dos fatores associados à autoconfiança possibilita propor estratégias educativas sistematizadas e efetivas, as quais certamente promoverão a autoconfiança dos professores e, consequentemente, um manejo seguro das principais intercorrências de saúde no ambiente escolar.

\section{Conclusão}

Neste estudo, objetivamos analisar as contribuições da simulação in situ na autoconfiança de professores da educação infantil e fundamental I com relação ao manejo inicial das intercorrências de saúde na escola e concluímos que os resultados apresentados atenderam o objetivo e responderam as questões de pesquisa.

A partir das análises estatísticas certificou-se que os professores sentem-se pouco confiantes para manejar intercorrências de saúde na escola, contudo, após simulação in situ observou-se promoção da autoconfiança, especialmente entre aqueles com menor tempo de experiência profissional, sem experiência anterior com situações semelhantes e que atuaram ativamente nos cenários simulados.

Deste modo, faz-se relevante a elaboração de atividades educativas que permitam um número maior de participantes ativos, respeitando o desejo e a disposição dos participantes. Faz-se necessário, também, novas investigações que comparem a promoção da autoconfiança entre atividades mediadas pela simulação e atividades educativas conduzidas tradicionalmente, ou seja, aquelas em que o aprendiz mantém postura passiva e o educador é o responsável pelo processo educativo, como as aulas teóricas.

\section{Referências}

1. Silva JVF, Silva EC, Silva EG, Ferreira AL, Rodrigues APRA. Perfil da morbidade hospitalar por doenças respiratórias na infância de 0 a 9 anos na cidade de Maceió - AL no período de 2008 a 2014. Cad Graduação - Ciências Biológicas e da Saúde UNIT-ALAGOAS. [Internet]. 2016 [Acesso 15 jan 201];3(3):43-5. Disponível em: https://periodicos.set. edu.br/index.php/fitsbiosaude/article/view/3130/2010

2. Pina JC, Moraes SA, Freitas ICM, Mello DF. Role of primary health care in child hospitalization due to pneumonia: a case-control study. Rev. Latino-Am. Enfermagem. [Internet]. 2017 [cited 2018 May 22];25:e2892. Available from: http://www.scielo.br/pdf/rlae/v25/pt_0104-1169rlae-25-e2892.pdf

3. Malta DC, Mascarenhas MDM, Neves ACM, Silva MA. Treatment of childhood injuries and violence in public emergency services. Cad Saúde Pública [Internet]. 2015 [cited 2018 May 22];31(5):1095-1105. Available from: http://www.scielo.br/pdf/csp/v31n5/0102-311Xcsp-31-5-1095.pdf

4. Oliveira ADS, Lopes AG, Lisboa JM, Campelo DML, Marinho CMM, Araujo ALSC. Performance of teachers to children in case of accidents at school. Rev Interdisciplinar UNINOVAFAPI. [Internet]. 2012 Jul [cited 2018 Jan 13];5(3):26-30. Available from: https://revistainterdisciplinar.uninovafapi.edu.br/ revistainterdisciplinar/v5n3/pesquisa/p4_v5n3.pdf

5. Copetti CL, Maciel GW, Daminelli CR, Gualtieri PD, Souza RL. Calls a teens accident victims of household in child in the south hospital materno Santa Catarina. Rev Inova Saúde. [Internet]. 2014 [cited 2017 Nov 12];3(2). Available from: http://periodicos.unesc.net/Inovasaude/ article/view/1310/1669.

6. Masih S, Sharma RK, Kumar A. Knowledge and practice of primary school teachers about first aid management of selected minor injuries among children. Int J Med Public Health.[Internet]. 2014 [cited 2018 Fev 13];4(4):458-62. Available from: http://ijmedph.org/sites/default/files/Int] MedPublicHealth_2014_4_4_458_144114.pdf. 
7. Galindo NM Neto, Caetano JA, Barros LM, Silva TM, Vasconcelos EMR. First aid in schools: construction and validation of an educational booklet for teachers. Acta Paul Enferm. [Internet]. 2017 [cited 2018 Mar 15];30(1):87-93. Available from: http://www.scielo.br/pdf/ape/v30n1/19820194-ape-30-01-0087.pdf.

8. Carvalho LS, Alarcão ALC, Barroso PD, Meireles GOAB. The Approach of First Aid Performed by Teachers in a State Educational Unit at Anapólis - GO. Ensaios Cienc Biol Agrar Saúde. [Internet]. 2014 [cited 2018 Mar 26];18(1):25-30. Available from: http://www.pgsskroton.com.br/seer/ index.php/ensaioeciencia/article/view/407/2899

9. Li F, Sheng X, Zhang J, Jiang F, Shen X. Effects of pediatric first aid training on preschool teachers: a longitudinal cohort study in China. BMC Pediatr. [Internet]. 2014 [cited 2018 May 24];14:2009. Available from: https://www.ncbi.nlm.nih.gov/pmc/articles/PMC4236654/ 10. Ngayimbesha A, Hatungimana O. Evaluation of first aid knowledge among elementary school teacher in Burundi. Int J Sports Sci Fitness. [Internet]. 2015 [cited 2018 Fev 10];5(2):304. Available from: http://www.ijssf.org/PDF/v05issue02abs13.pdf

11. Galindo NM Neto, Pereira JC, Muniz ML, Mallmann DG, Souza NMG, Neri MFS, et al. Health Education Intervention on First Aid in School: Integrative Review. Int Arch Med. [Internet]. 2016 [cited 2018 May 15];9(144):1-7. Available from: http://imed.pub/ ojs/index.php/iam/article/view/1733/1285

12. Joseph N, Narayanan T, bin Zakaria S, Nair AV, Belayutham L, Subramanian AM, et al. Awareness, attitudes and practices of first aid among school teachers in Mangalore, south India. J Prim Health Care. [Internet]. 2015 [cited 2018 Fev 24];7(4):274-81. Available from: https://www.ncbi.nlm.nih.gov/pubmed/26668832

13. Sena SP, Ricas J, Viana MRA. Perception of accidents in school by elementary level educators, Belo Horizonte. Rev Med Minas Gerais [Internet]. 2008 [cited 2017 Nov 13]; 18(4):47-54. Available from: http://www.rmmg.org/artigo/detalhes/1400.

14. Rodrigues KL, Antão JYFL, Sobreira GLS, Brito RN, Freitas GLS, Serafim SC, et al. Teacher's Knowledge about First Aid in the School Environment: Strategies to Develop Skills. Int Arch Med. [Internet]. 2015 [cited 2018 May 23];8(209):1-9. Available from: https://imed.pub/ ojs/index.php/iam/article/view/1295/1038.

15. Hwang JY, Oh ES, Cho KJ. A study on the selfconfidence in performance and education demand of first aid in kindergarten and daycare center teachers. J Korea Acad Industr Cooperat Soc. [Internet]. 2016 [cited 2018 Mar 23];17(1):234-43. Available from: http://www. koreascience.or.kr/article/JAKO201608160153476.page 16. Mazzo A, Martins AJC, Jorge BM, Batista RCN, Almeida RGS, Henriques FMS, et al. Validation of the self-confidence scale of nursing care in urinary retention. Rev Latino-Am. Enfermagem. [Internet]. 2015 [cited 2017 Jun 23];23(5):814-20. Available from: https:// www.revistas.usp.br/rlae/article/view/106127/104773

17. Kim SJ, Shin H, Lee J, Kang S, Bartlett R. A smartphone application to educate undergraduate nursing students about providing care for infant airway obstruction. Nurse Educ Today. [Internet]. 2017 [cited 2018 Jan 15];48:145-52. Available from: https://www.sciencedirect.com/science/article/pii/ S0260691716302350

18. Eze CN, Ebuehi OM, Brigo F, Otte WM, Igwe SC. Effect of health education on trainee teachers' knowledge, attitudes, and first aid management of epilepsy: An interventional study. Seizure. [Internet]. 2015 [cited 2018 Mar 12];3:46-53. Available from: https://www.sciencedirect. com/science/article/pii/S1059131115002502

19. Martins JCA, Baptista RCN, Coutinho VRD, Mazzo A, Rodrigues MA, Mendes IAC. Self-confidence for emergency intervention: adaptation and cultural validation of the Self-confidence Scale in nursing students. Rev. LatinoAm. Enfermagem. [Internet]. 2014 [cited 2018 Fev 22]; 22(4):554-61. Available from: http://www.periodicos. usp.br/rlae/article/view/86682/89699

20. Oliveira SN, Prado ML, Kempfer SS. Use of simulations in nursing education: an integrative. Rev Min Enferm. [Internet]. 2014 [cited 2018 Abr 12];18(2):487-95. Available from: http://www.reme.org.br/artigo/detalhes/941

21. Teixeira CRS, Pereira MCA, Kusumota L, Gaioso VP, Mello CL, Carvalho EC. Evaluation of nursing students about learning with clinical simulation. Rev Bras Enferm. [Internet]. 2015 [cited 2018 Mar 12];68(2):311-9. Available from: http://www.scielo.br/pdf/reben/v68n2/ en_0034-7167-reben-68-02-0311.pdf

22. Sorensen JL, Ostergaard D, LeBlanc V, Ottesen B, Konge $L$, Dieckmann $P$, et al. Design of simulation-based medical education and advantages and disadvantages of in situ simulation versus off-site simulation. BMC Med Educ [Internet]. 2017 [cited 2018 Jan 15];17:20. Available from: https://bmcmededuc.biomedcentral.com/track/pdf/10.1186/ s12909-016-0838-3

23. Posner GD, Clark ML, Grant VJ. Simulation in the clinical setting: towards a standard lexicon. Adv Simul. [Internet]. 2017 [cited 2018 Mar 13];2(1):15. Available from: https://advancesinsimulation.biomedcentral.com/track/ pdf/10.1186/s41077-017-0050-5

24. Alkhulaif A, Julie I, Barton J, Nagle E, Yao A, Clarke $S$, et al. Simulación in situ: ventajas, retos y obstáculos. Latin Am J Telehealth [Internet]. 2016 [cited 2018 Fev 12];3(2):141-149. Available from: http://cetes.medicina. ufmg.br/revista/index.php/rlat/article/view/139/279

25. Polit DF, Beck CT. Fundamentos da Pesquisa Clínica em Enfermagem: Avaliação da evidência para a prática de enfermagem. $7^{a}$ ed. Porto Alegre: Artmed; 2011. 
26. Zonta JB, Eduardo AH, Okido ACC. Self-confidence for the initial management of health issues in schools: construction and validation of a visual analogue scale. Esc Anna Nery. [Internet]. 2018 [cited 2019 Jan 10];22(4):e20180105. Available from: http:// www.scielo.br/pdf/ean/v22n4/1414-8145-ean-2204-e20180105.pdf

27. Chamberlain J. Prebriefing in Nursing Simulation: A Concept Analysis Using Rodger's Methodology. Clin Simul Nurs. [Internet]. 2015 [cited 2019 Jan 10];11(7):31822. Available from: https://www.sciencedirect.com/ science/article/pii/S1876139915000420

28. Jeffries PR. Simulation in nursing education: from conceptualization to evaluation. New York: National League for Nursing; 2007.

29. Fisher LD, Van Belle GV. Biostatistics: a methodology for the health sciences. New York: Wiley, 1993. 991p.

30. Calandrim LF, Santos AB, Oliveira LR, Massaro LG, Vedovato CA, Boaventura AP. First aid at school: teacher and staff training. Rev Rene. [Internet]. 2017 [cited 2018 Fev 13];8(3):292-9. Available from: http:// periodicos.ufc.br/rene/article/viewFile/20044/30695 31. Abrantes AWB, Coura EMG, Bezerra ALD, Assis EV, Feitosa ANA, Freitas MA, et al. Knowledge, atitudes and nursing practices on cardiorespiratory arrest in neonatal intermediate care unit: a qualitative study in the northeast of Brazil. ] Hum Growth Dev. [Internet]. 2015 [cited 2018 Fev 20];25(1):97-101. Available from: http:// www.periodicos.usp.br/jhgd/article/view/96787/96181 32. Silva LGS, Costa JB, Furtado LGS, Tavares JB, Costa JLD. First aid and prevention of accidents in the school environment: intervention in the educational unit. Enferm Foco. [Internet]. 2017 [cited 2018 Jan 12];8(3):25-9. Available from: http://revista.cofen.gov. br/index.php/enfermagem/article/view/893/394

33. Machado, ECM, Petry AR, Somavilla VEC, Hopp LS. Accidents in childhood: perception and atitudes of teachers in child education. Rev Saúde Desenvolv. [Internet]. 2017 [cited 2018 Jan];11(7). Available from: https://www.uninter.com/revistasaude/index.php/ saudeDesenvolvimento/article/view/602/392

34. Ramos AM, Barlem JG, Lunardi VL, Barlem ELD, Silveira RS, Bordignon SS. Satisfaction with academic experience among undergraduate nursing students.
Texto Contexto Enferm. [Internet]. 2015 [cited 2018 Jan 9];24(1):187-95. Available from: http://www.scielo. br/pdf/tce/v24n1/pt_0104-0707-tce-24-01-00187.pdf

35. Costa RRO, Medeiros SM, Martins JCA, Cossi MS, Araújo MS. Perception of undergraduate nursing students on realistic simulation. Rev Cuidarte. [Internet]. 2017[cited 2018 Jan 13];8(3):1799-808. Available from: http://www.scielo.org.co/scielo.php?script=sci_ar ttext\&pid=S2216-09732017000301799

36. Mazzo A, Martins JCA, Baptista RCN, Godoy S, Coutinho VRD, Seixas $C A$, et al. A Simulação e a Videoconferência no Ensino de Enfermagem. Rev Grad USP. [Internet]. 2017 [cited 2018 Fev 20];2(2):55-63. Available from: http://gradmais.usp.br/wp-content/ uploads/2017/07/Gradmais4_A07_Mazzo.pdf

37. Baptista RCN, Martins JCA, Pereira MFR, Mazzo A. Students' satisfaction with simulated clinical experiences: validation of an assessment scale. Rev Latino-Am. Enfermagem. [Internet]. 2014 [cited 2018 Jan 13];22(5):709-15. Available from: http://www.scielo.br/ pdf/rlae/v22n5/0104-1169-rlae-22-05-00709.pdf

38. Martins JCA, Coutinho VR, Baptista RC, Oliveira LM, Gonçalves RF, Paiva LA, et al. Impact of a simulated practice program in the construction of self-confidence for intervention in emergencies and its association with knowledge and performance. J Nurs Educ Pract. [Internet]. 2017 [cited 2018 Jan 28];7(1):45-50. Available from: http://www.sciedu.ca/journal/index. php/jnep/article/view/9536/6148

39. Park SL, Kim JS. Factors affecting daycare center teachers' management of childhood fever. Child Health Nurs Res. [Internet]. 2016 [cited 2018 Mar 24];22(4):289-98. Available from: https://www.e-chnr.org/journal/view. php?doi=10.4094/chnr.2016.22.4.289
Recebido: 26.08.2018

Aceito: 09.04.2019
Copyright $\odot 2019$ Revista Latino-Americana de Enfermagem Este é um artigo de acesso aberto distribuído sob os termos da Licença Creative Commons CC BY.

Esta licença permite que outros distribuam, remixem, adaptem e criem a partir do seu trabalho, mesmo para fins comerciais, desde que Ihe atribuam o devido crédito pela criação original. É a licença mais flexível de todas as licenças disponíveis. É recomendada para maximizar a disseminação e uso dos materiais licenciados. 